\title{
Systematic monetisation of environmental impacts
}

\author{
H. Krieg, S. Albrecht \& M. Jäger \\ Department of Life Cycle Engineering (GaBi), Chair of Building Physics, \\ University of Stuttgart, Germany
}

\begin{abstract}
Integrating environmental aspects in planning and controlling processes is an increasing challenge for companies and organisations, especially in times of growing environmental awareness of customers and increasing regulative pressure. Monetisation of environmental impacts can help here to include environmental impacts of products and processes in established planning and controlling structures and thereby contribute to organisational sustainability efforts. The method proposed here allows for a systematic integration of environmental impacts and economic factors. It does so by using the simplex algorithm, a heuristic approach that is used in classic business theory for, for example, planning of production processes within companies. The approach presented is based on the outcomes of a Life Cycle Assessment of products and processes. Furthermore, all environmental aspects to be included in the planning have to be limited. Such limitation can come, for example, from an organisation's environmental policy. Resources with unlimited availability are considered to be free of charge in business theory and can therefore not be monetised. Through the limitation towards a target value, scarcity is created. Through the iterative application of the simplex algorithm, an optimal allocation of the scarce resources, in this case environmental impacts, can be reached. The approach thereby allows for systematically planning programs with the constraint of limited environmental impact. This results in a portfolio that fulfils the goal of reduced environmental impact with minimal costs, while also giving information on the internal value of scarce parameters, such as emissions, through shadow prices.
\end{abstract}

Keywords: monetisation, LCA, portfolio planning, reducing impacts, environmental policy, carbon tax, carbon trading, linear optimisation. 


\section{Introduction}

Monetisation of environmental impacts describes the effort of expressing emissions into the environment in monetary values with the goal of an economic quantification of environmental damage caused through a product or process, which then can be the basis for a monetary incentive to avoid said impacts (Beckenbach et al. [1]). Current approaches for the monetisation of environmental impacts are mostly based on a separate assessment of both economic and environmental factors that are then combined retrospectively. Due to the retrospective approach, it is hard to use monetisation for planning processes, as it is always delayed to actual organisational actions (Schultz [2]). Most approaches for the monetisation of environmental impacts are based on the willingness to pay, which again is a quite subjective measure as for each region, individual or organisation and situation this willingness can vary (Reap et al. [3]).

Other approaches focus on determining the actual environmental damage costs caused through environmental impacts. This again is based on soft criteria. An analysis found that the environmental damage costs for the same system can differ by a factor of 40,000 (German Federal Environment Agency UBA [4]). Due to those problems, monetisation of environmental impacts is still an unresolved issue for Life Cycle Assessment (LCA) practitioners.

The approach presented within this paper picks up at this point. It offers an integrated approach that allows combining environmental aspects with economic factors in an objective way and avoids using subjective or soft criteria to determine a monetary value for environmental impacts. The determination of monetary value is hereby calculated organisation specific. That means that the outcomes of the assessment are only valid for the given situation and is not generally valid for other organisations or situations. Still, it offers a method of objectively determining the internal value of environmental impacts of an organisation. It does so by using the simplex algorithm in order to optimise a company's portfolio while establishing a price for environmental impacts. In a first step, the underlying methodologies used within the presented approach are explained, followed by a description of the integrated approach for monetisation as well as a case study that shows the application of this method. Results of the assessment are then discussed and interpreted. The article ends with a conclusion on the potential of the method and an outlook.

\section{Methodological approach}

\subsection{Life cycle assessment}

Life Cycle Assessment (LCA) is a method widely accepted and applied in industry and science. It allows quantifying the environmental impacts of products, processes and services and is standardised in ISO 14040 [5] and 14044 [6]. Within those standards, requirements for the method to ensure transparency and reproducibility of are defined. Through the quantification of 
environmental impacts, LCA supports environmental product improvement, strategic planning, benchmarking with other technologies or products as well as decision making. LCA is based on life cycle thinking; therefore all life cycle stages during a products life are assessed, from raw material extraction, material production, manufacturing over utilisation to end of life. For those life cycle stages, all energy carriers, materials and auxiliaries as well as waste and emissions are taken into account and summed up.

This life cycle approach avoids shifting environmental impacts from one life cycle stage to another. Through the consideration of the entire life cycle, total environmental impacts are taken into account, allowing for a systematic analysis and reduction of environmental impacts using a well-established method.

As LCA requires a lot of data on inputs, outputs and their respective impact on the environment, software tools such as the GaBi LCA [7] software are used. This allows creating environmental models of products and processes, using extensive background databases with information on environmental impacts of different materials, processes or products. The results of an LCA are expressed in impact categories such as Global Warming Potential (GWP) and characterised by their significance in relation to a reference unit, e.g. $\mathrm{kg} \mathrm{CO}_{2}$-equivalent for GWP. This allows taking systematic steps for product improvements, benchmarking or strategic decision making.

\subsection{Environmental aspects in business theory}

Goods can be classified according to several criteria. An example of this is the classification based on excludability and rivalry in consumption. Excludability is based on whether it is possible to exclude individuals from the consumption of such goods. An example can be a levee and pay-tv. No one can be excluded from the benefits of a levee, as it protects everybody behind it. On the other hand, individuals can be excluded from the consumption of pay-tv, simply not by activating the channels. Rivalry in consumption describes an interference of the usability of a good that is being used by another individual. An example can be breathing and bread. Under normal conditions, no one's potential to breath is influenced by other breathing organisms around. On the other hand, an individual's potential to consume bread is strongly impacted by the consumption of said bread through another individual. Based on those criteria, four categories of goods exist, as shown in Figure 1 (Endres and Martiensen [8]).

\begin{tabular}{|c|c|c|}
\hline & $\begin{array}{l}\text { No rivalry of } \\
\text { consumption }\end{array}$ & $\begin{array}{l}\text { Rivalry of } \\
\text { consumption }\end{array}$ \\
\hline Non-excludable & $\begin{array}{l}\text { Public goods } \\
\text { e.g. levee }\end{array}$ & $\begin{array}{l}\text { Common goods } \\
\text { e.g. environment }\end{array}$ \\
\hline Excludable & $\begin{array}{l}\text { Club goods } \\
\text { e.g. pay-tv }\end{array}$ & $\begin{array}{l}\text { Private goods } \\
\text { e.g. food }\end{array}$ \\
\hline
\end{tabular}

Figure 1: Classification of goods. 
The environment is here categorised as a common good. Individuals can't be excluded from using it, while there is a rivalry of consumption. This is described as the so-called Tragedy of the Commons, postulated by Hardin [9]. As an example, he uses grazing land open to all. Several shepherds use it to feed their cattle. Each shepherd, being a rational actor, tries to maximise his earning, which can be achieved by increasing the size of his herd. This has two opposing effects. For the shepherd, the earning is increased by the benefit he has from having more cattle. On the other side, the same grazing land has now to accommodate one additional cattle to feed. However, this effect is smaller for a single shepherd, as it is shared by all shepherds. Therefore the rational decision for each shepherd in this example is to add more cattle to his herd. This is the tragedy of the commons: while each individual follows his own rational agenda to maximize his earning; the total availability of grazing land is limited. So while pursuing their own best interest, the group of shepherds is driving themselves to ruin. The same is the case for pollution and emissions, only in a reverse way. Instead of consuming too much of a limited resource, something is emitted in a system that has only a limited capacity to hold those emissions. Again, each actor will find that it is cheaper for him to emit into the common good environment and pay his share of the costs to compensate the impact, than to pay for the actual costs of avoiding or purifying his waste and emissions (Hardin [9]). From an economic point of view, the rational thing is therefore to rather participate in social repair costs, e.g. in form of tax than to take more expensive individual measures to reduce an organisations environmental impact.

On the other hand, environmental awareness in society, industry and politics has grown over the last years. Politics impose laws that aim at preserving the environment (European Commission [10]) while customers awareness for the environmental impacts of products and services increased. Industry answered to these new challenges through organisational environmental policy, sustainable product design or systematic improvement of products and processes, e.g. based on LCA studies. As a result, sustainability efforts of companies become a competitive factor, as it can be used to diversify own products and services from those of competing organisations (Meffert and Kirchgeorg [11]). Especially in saturated markets, diversification can be an important step to get a competitive edge over other organisations. This rising awareness and measures taken due to it can help to solve the tragedy of the commons.

\subsection{The simplex algorithm for portfolio planning}

The simplex algorithm is a method presented by George Dantzig that allows solving linear optimisation problems (Dantzig [12]). In classical business theory, it is e.g. used to identify optimal production programs with the constraint of limited availability of machining time and/or materials. In a first step the target value to be optimised has to be selected. The Contribution to Margin (CtM) is here often selected; as it takes into account both costs and revenues related to a product. The Contribution to Margin (CtM) is the key parameter for short-term production planning. The CtM is generally the difference between the selling price and the variable costs of a product (Wöhe and Döring [13]). Both target 
value and constraints are then transferred in a matrix structure (see Table 2 in section 3). Starting from a basic feasible solution, it takes iterative steps to find a solution better than the previous one. This is done until an optimal allocation of available resources is reached. The basic feasible solution is often chosen with a total Contribution to Margin of zero, correlating to not using any means of production, while generating no income at all. From this feasible solution, pivot operations are conducted in order to improve increase the target value and reach an optimal allocation of scarce resources (Geiger and Kanzow [14]). The application of the simplex algorithm is described within the case study.

\subsection{Integrated approach for systematic monetisation of environmental impacts}

In a next step, the previously presented methodological approaches are combined to an integrated approach for the systematic monetisation of environmental impacts. The procedure of this is shown in Figure 2.

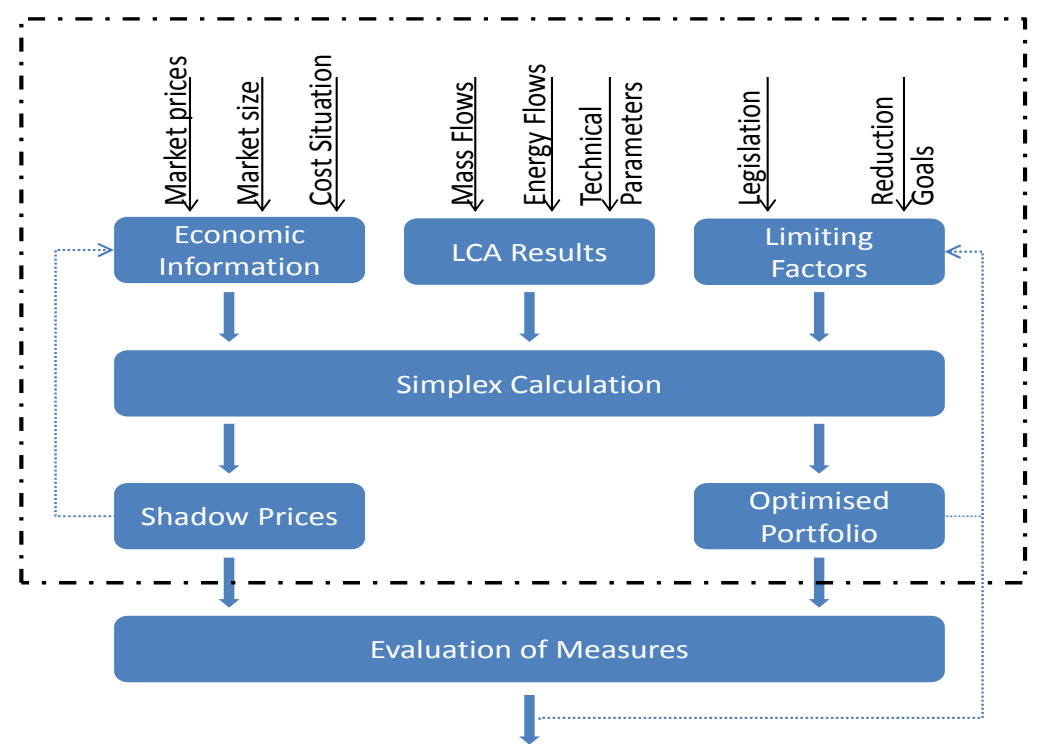

Figure 2: $\quad$ Integrated methodological approach.

Economic factors such as market prices, market share and product prices deliver the required economic information. At the same time, LCA studies are conducted for all products under assessment, giving out the environmental profiles of products based on mass and energy flows. Finally, there are limiting factors, e.g. legislation or reduction goals, that put a certain boundary to the amount of environmental impacts. All those factors are used as input parameters for the simplex calculation. This calculation aims at an optimal allocation of scarce factors, in this case environmental impacts. It thereby allows reaching environmental reduction goals with minimal economic impact. The output is an optimised portfolio, which results in the largest economic success under the 
given constraints. Furthermore, shadow prices are calculated. Those determine the internal value of scarce factors. This can then be used to prioritise measures or to compare the internal value of scarce factors with external prices, e.g. coming from an emission trading scheme.

\section{Case study}

The application of the simplex method as a tool for portfolio planning with the consideration of environmental impacts is presented through a case study. The case study is based on a virtual logistics company. This company operates a portfolio of multi-use plastic crates for the transport of fruits and vegetables and aims at optimising this portfolio with consideration of environmental aspects. The value to be optimised is selected to be the contribution to margin (CtM) of both products. There are two kinds of crates available, one made of conventional, crude oil based polyethylene (PE) and one made of polyethylene based on the renewable feedstock sugar cane, each with its own environmental profile but identical technical properties. The composition of the portfolio will thereby impact the company’s environmental impact.

The environmental information is based on a study conducted by the Department Life Cycle Engineering of Fraunhofer IBP and University of Stuttgart on behalf of Stiftung Initiative Mehrweg (Albrecht et al. [15]). Within this study, the life cycle of multi-use plastic crates for the transportation of fruits and vegetables in Europe was assessed and quantified through an LCA study. Environmental data models, assumptions, documentation of system boundaries as well as results have been subject to a critical review according to ISO $14040 / 44$. The quality of the data is therefore very high.

Subject of the study are among other multi-use plastic crates. Those crates have a weight of $2 \mathrm{~kg}$ and a capacity of $15 \mathrm{~kg}$ of fruit or vegetables. Logistic processes take place between five selected producing countries and four consuming countries, respectively representing the most important markets within the European Union. The study covers initial production of crates, replacement of broken crates during use, transport, washing of used crates and recycling of crates at their end of life. Life span of plastic crates is assumed to be 10 years and 5 fillings per year, corresponding to 50 circulations per crate total.

For those system boundaries and same underlying assumptions as realised in the study mentioned above, two multi-use plastic crates are analysed, one made of conventional crude oil based polyethylene as in the original study and the other made of bio-based polyethylene from sugar cane.

Based on those assumptions and system boundaries, environmental data models are created within the GaBi LCA software [7]. The model is evaluated in order to identify the environmental impacts of the entire life cycle of the plastic crates. Results of the LCA study for both packaging systems are expressed in impact indicators. Those impacts are shown in Table 1. All properties refer to one circulation of each system. For the sake of simplicity, the LCA is not described here in detail. 
Economic aspects differ from organisation to organisation; no general statements can be given here. Therefore assumptions on the CtM have to be made for this case study. It is assumed that per circulation of a conventional PE crate the CtM is $0.50 €$, due to the higher production costs for sugar cane based $\mathrm{PE}$ crates, the CtM is set to $0.45 €$.

For the sake of simplicity, this case study only takes two environmental impact categories into account, Global Warming Potential (GWP, expressed in $\mathrm{kg} \mathrm{CO}_{2}$-equivalent) and Acidification Potential (AP, expressed in $\mathrm{kg}$ $\mathrm{SO}_{2}$-equivalent).

Table 1: $\quad$ Product properties per circulation.

\begin{tabular}{|c|c|c|c|}
\hline & GWP [kg $\mathrm{CO}_{2}$-eq.] & $\mathrm{AP}$ [kg SO $\mathrm{SO}_{2}$-eq.] & $\mathrm{CtM}[€]$ \\
\hline Conventional PE crate & 0.33 & 0.0015 & 0.50 \\
\hline Bio-based PE crate & 0.10 & 0.0025 & 0.45 \\
\hline
\end{tabular}

It is assumed that the company currently operates a portfolio that consists of respectively $50 \%$ of each type of crate. The total number of circulations is $3,333,350$, corresponding to the transportation of $50,000 \mathrm{t}$ of fruits and vegetables. Therefore, 1,666,675 circulations of each type of crate carried out.

In a first step, the current environmental impact is determined. This can be done by multiplying the number of crates with the respective environmental profile of one circulation. Based on this, the environmental profile sums up to $717,500 \mathrm{~kg} \mathrm{CO}$-eq. and 6,667 $\mathrm{kg}$ of $\mathrm{SO}_{2}$-eq. while generating a total $\mathrm{CtM}$ of $1,583,341 €$. Apart from the environmental restrictions, there is also a market restriction; the total amount of circulations can't be higher than 3,333,350.

The company now aims at optimising their environmental profile. Therefore, the product properties as well as the restrictions are transferred in a simplex starting tableau with a basic feasible solution. Table 2 shows the first simplex tableau. The first two columns represent the product properties for conventional $(\mathrm{Y})$ and bio-based crates $(\mathrm{X})$ that were already shown in Table 1. Columns S1S3 are slack variables that transform the inequations into an equation. The column on the right quantifies the limitations. RHS stands hereby for Right Hand Side. These are the environmental and market-based limitations for the portfolio. The first numerical line in the tableau represents contribution to GWP. The number in the RHS-column describes the yet available amount. The second numerical line represents AP; the third line the market restriction with a maximum number of circulations of 3,333,350. The numbers in the table represent the negative marginal impact of an increase of the product or slack variable in that line on the RHS.

Table 2: $\quad$ Simplex tableau basic feasible solution.

\begin{tabular}{|c|c|c|c|c|c|c|}
\hline \multirow{4}{*}{$\begin{array}{c}\text { GWP } \\
\text { AP } \\
\text { Market }\end{array}$} & $\mathbf{X}$ & $\mathbf{Y}$ & S1 & $\mathrm{S} 2$ & S3 & RHS \\
\hline & 0.1000 & 0.3300 & 1 & 0 & 0 & 717,500 \\
\hline & 0.0025 & 0.0015 & 0 & 1 & 0 & 6,667 \\
\hline & 1 & 1 & 0 & 0 & 1 & $3,333,350$ \\
\hline & -0.45 & -0.50 & 0 & $\mathbf{0}$ & 0 & 0 \\
\hline
\end{tabular}


The bottom line is the target function, containing the CtM of each product, while on the RHS the organisations total CtM is shown. In this case it is still zero, as the basic feasible solutions starts with an output of zero before taking iterations to optimise the outcome.

On the very left, the restriction to which the line relates is named. Note that this will change when applying the simplex method, depending where a pivot line with one " 1 " and the rest " 0 " is. Values on the RHS always correspond to the line where the " 1 " is found, representing the variable in the column of the " 1 ".

Starting from this basic feasible solution, iterative steps are taken to optimise the portfolio. Within each iterative step, a column is selected, for example the one with the largest negative number in the target function line, as it has the strongest marginal impact on the target value. From the selected column the pivot element is chosen by dividing the number in the right column by the respective number in the previously chosen column and choosing the line with the smallest number as pivot element. In this case, the pivot column is Y, the pivot element is the contribution of product Y to GWP in the first line. The pivot line is then divided by the pivot element, so that the pivot element has a value of 1 . In a next step, multiples of the pivot row are subtracted from the other rows so all non-pivot elements in the pivot column become 0 . In the next step, another negative value from the target function line is selected and the steps are repeated. This is done until there are no negative values in the target function line left. As soon as this is the case, the available resources are allocated in an optimal way, as no adaption of the portfolio can increase the CtM anymore. Based on this allocation, shadow prices of scarce resources are determined. Those shadow prices describe the internal value of each respective resource in the current organisation-specific situation (Geiger and Kanzow [14]).

In a first step it is analysed if the current portfolio is optimal. Therefore, a simplex analysis is run with constant constraints. The result is shown in Table 3.

Table 3: $\quad$ Simplex tableau optimised basis scenario.

\begin{tabular}{c|r|r|r|r|r|r|}
\cline { 2 - 7 } \multicolumn{1}{c|}{ Y } & Y & \multicolumn{1}{c|}{ S1 } & \multicolumn{1}{c|}{ S2 } & \multicolumn{1}{c|}{ S3 } & \multicolumn{1}{c|}{ RHS } \\
\cline { 2 - 7 } AP & 0 & 1 & 4.330 & 0 & -0.430 & $\mathbf{1 , 6 6 6 , 6 7 5}$ \\
\cline { 2 - 7 } X & 0 & 0 & 0.004 & 1 & -0.003 & $\mathbf{0}$ \\
\cline { 2 - 7 } & 1 & 0 & -4.330 & 0 & 1.430 & $\mathbf{1 , 6 6 6 , 6 7 5}$ \\
\cline { 2 - 7 } & $\mathbf{0}$ & $\mathbf{0}$ & $\mathbf{0 . 2 2 0}$ & $\mathbf{0}$ & $\mathbf{0 . 4 3 0}$ & $\mathbf{1 , 5 8 3 , 3 4 1}$ \\
\hline
\end{tabular}

It can be seen that the lines now relate to different parameters, as the pivot columns and thereby the reference value of the pivot element changes. Both $X$ and $\mathrm{Y}$ have an output of 1,666,675, generating a total CtM of 1,583,341 $€$. This means that the original portfolio represents an optimal allocation of available factors. In this case, this is not surprising, as one product has a lower GWP, while the other has a lower contribution to AP. In order to have the largest benefit from the available parameters, the original split is a logical consequence. 
In a next step, the company aims at reducing its environmental impact. It is decided to reduce GWP by $10 \%$. This results in adapted constraints of the simplex tableau, as the maximum emission of $\mathrm{CO}_{2}$-equivalents is now only $90 \%$ of the original level. Based on the new constraints, the simplex analysis is run again. The outcome of this optimisation is shown in Table 4.

Table 4: $\quad$ Simplex tableau optimised with GWP-reduction.

\begin{tabular}{c|r|r|r|r|r|r|}
\cline { 2 - 8 } & $\mathbf{X}$ & $\mathbf{Y}$ & \multicolumn{1}{c|}{ S1 } & \multicolumn{1}{c|}{ S2 } & \multicolumn{1}{c|}{ S3 } & \multicolumn{1}{c|}{ RHS } \\
\cline { 2 - 8 } Y & 0 & 1 & 3.69 & -147 & 0 & $\mathbf{1 , 4 0 1 , 7 3 7}$ \\
\cline { 2 - 8 } X & 1 & 0 & -2.21 & 488 & 0 & $\mathbf{1 , 8 2 5 , 6 3 7}$ \\
\cline { 2 - 8 } & 0 & 0 & -1.47 & -341 & 1 & $\mathbf{1 0 5 , 9 7 6}$ \\
\cline { 2 - 8 } & $\mathbf{0}$ & $\mathbf{0}$ & $\mathbf{0 . 8 5}$ & $\mathbf{1 4 6}$ & $\mathbf{0}$ & $\mathbf{1 , 5 2 2 , 4 0 5}$ \\
\cline { 2 - 7 } & & & & & &
\end{tabular}

As the acceptable amount of $\mathrm{CO}_{2}$-emissions is reduced, the portfolio changes. The new portfolio now consists of about 1,402,000 conventional PE crates and $1,826,000$ crates made of sugar cane based PE. This results in a total of $3,228,000$ circulations, generating a total CtM of 1,522,405 €. In this situation, the market still has an unsaturated demand of almost 106,000 circulations. As it can be seen, a reduction of the companies' contribution to GWP by $10 \%$ can be realized by changing the portfolio and without taking other steps. This results in a reduction of the total CtM by 3.8\%. The total market saturation is then down to 97\%. Under the new constraints, the highest possible CtM was realized, therefore fulfilling the environmental reduction target at the lowest possible reduction of CtM. Still, in this scenario, the company would lose some of its market share, as it can't saturate the entire demand of the market.

The company therefore wants to assess whether a bio-based crate that is produced in sustainable agriculture is a reasonable extension of the portfolio. It can be expected that the environmental impacts of such a product are lower, e.g. by not relying on slash-and-burn agriculture. This on the other hand causes higher production costs and thereby a lower CtM. An adapted LCA for the new product is conducted and its results are used as parameters in the simplex algorithm. Again, the goal is to reduce the contribution to GWP by $10 \%$ while not increasing the contribution to AP. The calculated environmental impacts per circulation are $0.08 \mathrm{~kg}$ of $\mathrm{CO}_{2}$-eq. and $0.002 \mathrm{~kg}$ of $\mathrm{SO}_{2}$-eq., while it is assumed that the CtM is only $0.42 €$ due to higher production costs. Furthermore, it is assumed that all three crates have the same technical properties and no additional costs are caused by introducing an additional type of material, namely the biobased PE from sustainable production without slash-and-burn agriculture here referred to as " $Z$ ". The new situation results in an updated simplex tableau with a new basic feasible solution, as shown in Table 5.

Based on this new situation, the simplex algorithm is now applied again. The results of this are presented in Table 6.

As can be seen, the total amount of circulations can remain at 3,333,350, so no market share is lost. To saturate the demand, 518,990 circulations of sustainable bio-based PE crates are used. Furthermore, the total CtM is higher by 32,400 € compared to the basis reduction scenario. Even though the bio-based PE crate 
Table 5: $\quad$ Basic feasible solution for product alternative with GWP-reduction.

\begin{tabular}{c|r|r|r|r|r|r|r|}
\multirow{4}{*}{ GWP } & \multicolumn{1}{c|}{$\mathbf{X}$} & \multicolumn{1}{c|}{ Y } & \multicolumn{1}{c|}{ Z } & \multicolumn{1}{c|}{ S1 } & \multicolumn{1}{c|}{ S2 } & \multicolumn{1}{c|}{ S3 } & \multicolumn{1}{c|}{ RHS } \\
\cline { 2 - 8 } AP & 0.1000 & 0.3300 & 0.080 & 1 & 0 & 0 & $\mathbf{6 4 5 , 8 0 0}$ \\
\cline { 2 - 8 } Market & 0.0025 & 0.0015 & 0.002 & 0 & 1 & 0 & $\mathbf{6 , 6 6 7}$ \\
\cline { 2 - 8 } & 1 & 1 & 1 & 0 & 0 & 1 & $\mathbf{3 , 3 3 3 , 3 5 0}$ \\
\cline { 2 - 8 } & $\mathbf{- 0 . 4 5}$ & $\mathbf{- 0 . 5}$ & $\mathbf{- 0 . 4 2}$ & $\mathbf{0}$ & $\mathbf{0}$ & $\mathbf{0}$ & $\mathbf{0}$ \\
\cline { 2 - 8 }
\end{tabular}

from sustainable agriculture looks at first sight less favourable from an economic point of view, it can contribute to the organisations business success. A comparison of the shadow prices of scarce factors shows that the situation is less stressed as the shadow prices are lower. Compared to the basis scenario, the total $\mathrm{CtM}$ is $28,500 €$ lower than in the initial situation. A reduction of more than $71 \mathrm{t}$ of CO2-eq. can therefore be reached only through a change of the portfolio mix and the introduction of a new product variant for costs of 28,500 $€$. Compared to the best solution with the established crates, this increases the company's total CtM by almost 33,000 €.

Table 6: Optimised simplex tableau for product alternative with GWP-reduction.

\begin{tabular}{l|r|r|r|r|r|r|r|}
\multicolumn{1}{c|}{ X } & \multicolumn{1}{c|}{ Y } & \multicolumn{1}{c|}{ Z } & \multicolumn{1}{c|}{ S1 } & \multicolumn{1}{c|}{ S2 } & \multicolumn{1}{c|}{ S3 } & \multicolumn{1}{c|}{ RHS } \\
\cline { 2 - 8 } $\mathrm{Y}$ & 0 & 1 & 0 & 3.6 & -165.0 & 0.1 & $\mathbf{1 , 4 0 7 , 1 8 0}$ \\
\cline { 2 - 8 } $\mathrm{Z}$ & 1 & 0 & 0 & 3.6 & 1.8 & -3.9 & $\mathbf{1 , 4 0 7 , 1 8 0}$ \\
\cline { 2 - 8 } & 0 & 0 & 1 & -7.2 & -1.7 & 4.9 & $\mathbf{5 1 8 , 9 9 0}$ \\
\hline & $\mathbf{0}$ & $\mathbf{0}$ & $\mathbf{0}$ & $\mathbf{0 . 4}$ & $\mathbf{4 1 . 9}$ & $\mathbf{0 . 3}$ & $\mathbf{1 , 5 5 4 , 7 9 7}$ \\
\hline
\end{tabular}

\section{Results and discussions}

Through the application of the proposed method, environmental reduction goals of organisations can be reached by adapting their product portfolio with the lowest possible economic impact. In the first case, a reduction of $71,750 \mathrm{~kg}$ of $\mathrm{CO}_{2}$-equivalents was realised through changing the portfolio. This results in a reduction of the total $\mathrm{CtM}$ by $61,000 €$. This corresponds to $0.85 € / \mathrm{kg} \mathrm{CO}_{2}$-eq. This value is referred to as the shadow price. It describes the internal value of one unit of a scarce factor in the current situation of a company. As it can be seen, this value is also shown in the bottom line under S1 in Table 4. The simplex algorithm describes the scarcity of all factors through their shadow price. For AP (represented through S2), this shadow price is $146 € / \mathrm{kg} \mathrm{SO}_{2}$-eq. This means that the emission of one additional $\mathrm{kg} \mathrm{SO}_{2}$-eq., the total CtM can be increased by $146 €$ in the organisations current situation, while the emission of one additional $\mathrm{kg}$ of $\mathrm{CO}_{2}$-eq. will increase the total $\mathrm{CtM}$ by $0.85 €$. This can be the basis on which an organisation can decide e.g. whether or not to buy $\mathrm{CO}_{2}$ certificates.

For the second application example with sugarcane grown in sustainable agriculture it could be seen that even the introduction of an at first sight 
economically not favourable product can contribute to the success of an organisation. For the situation assessed here, the introduction of a third product variant is a good choice, as it allows to fully saturate the demand of the market while increasing the total CtM of the organisation. Through the new product, the contribution to GWP could be reduced while other environmental impacts remain the same while reducing the costs compared to basis scenario. At the same time, the total CtM could be increased by over $32,400 €$ compared to the first scenario, while the entire demand of the market is saturated.

As it could be seen, the presented approach allows for an objective and systematic monetisation of environmental impacts. It uses economic information, environmental profiles of products and limiting factors in order to determine an optimal allocation of all scarce factors, by minimizing the economic impact. This can give decision makers a basis on which they can decide whether or not to take measures to reduce environmental impacts; to introduce new products or if and to what extent to by emission certificates.

\section{Conclusion and outlook}

This paper describes a systematic approach for monetizing environmental impacts as well as ways to improve environmental performance of organisations with the lowest possible economic impact. The described approach is therefore a valuable extension of current monetisation methods. Through the systematic and objective combination of ecologic and environmental aspects, it helps to include the outcomes of LCA studies in existing management procedures and thereby increases the relevance of LCA for decision making support.

As it could be seen in the case study, an optimal portfolio and thereby an optimal allocation of scarce factors, is reached through the application of the simplex algorithm with the smallest possible economic impact. Furthermore, shadow prices for scarce factors are calculated. Those can help companies with their decision making; e.g. the costs of measures to reduce emissions can be compared with the internal value of the reduction and thereby give information on the efficiency of measures. Also, the monetisation of environmental impacts can be the basis for internal programs, such as e.g. a carbon tax, as it helps to determine the price of such a tax. Another application shown is the evaluation whether to introduce a new product variant in order to fulfil environmental targets.

Those possibilities make the described methodological approach a useful extension of current approaches for the monetisation of environmental impacts, which again helps to increase the relevance of LCA for organisational decision making and thereby supports overall sustainability efforts. It helps organisations to define priorities when it comes to choose measures to reduce the environmental impact through shadow prices; a higher shadow price means a higher priority for measures that reduce the respective impact. Furthermore, objectively determined internal costs can be compared to external costs, e.g. for emission certificates or trade-off costs and thereby allows to systematically enhance sustainability efforts. 


\section{References}

[1] Beckenbach, F., Hampicke U. and Schulz, W., Möglichkeiten und Grenzen der Monetarisierung von Natur und Umwelt, Schriftenreihe des IÖW 20/88, Berlin, pp. 3-18, 1998.

[2] Schultz, A.; Integrated environmental and economic assessment of production processes and technologies. Doctoral Dissertation accepted by: Otto-von-Guericke-Universität Magdeburg, The Faculty of Engineering, pp. 13-31, 2002.

[3] Reap, J., Roman F., Duncan, S. and Bras, B., A survey of unresolved problems in life cycle assessment - part 2: impact assessment and interpretation Int Journal of Life Cycle Assessment, pp. 374-388, 2008.

[4] German Federal Environment Agency UBA, Ökonomische Bewertung von Umweltschäden - Methodenkonvention zur Schätzung externer Umweltkosten, pp. 7-14, 2007. http://www.umweltdaten.de/publikationen /fpdf-l /3193.pdf

[5] ISO 14040:2006: Environmental management - Life cycle assessment Principles and framework.

[6] ISO 14044:2006, Environmental management - Life cycle assessment Requirements and guidelines.

[7] PE: GaBi 5. Software-System and Databases for Life Cycle Engineering. Copyright, TM. Stuttgart, Echterdingen 1992-2012.

[8] Endres, A. and Martiensen, J., Mikroökonomik. Eine integrierte Darstellung traditioneller und moderner Konzepte in Theorie und Praxis, Kohlhammer-Verlag: Stuttgart, p. 768, 2007.

[9] Hardin, G., The Tragedy of the Commons. Science, New Series, Vol. 162, No. 3859 (Dec. 13, 1968), pp. 1243-1248, 1968.

[10] European Commission (2003), Directive 2003/87/EC of the European Parliament and of the Council of 13 October 2003 establishing a scheme for greenhouse gas emission allowance trading within the Community and amending Council Directive 96/61/EC.

[11] Meffert, H. and Kirchgeorg, M., Marktorientiertes Umweltmanagement. Konzeption, Strategie, Implementierung, Schaeffer-Poeschel-Verlag: Stuttgart, pp. 23-27, 1998.

[12] Dantzig, G., Linear Programming and Extensions. Princeton University Press: Princeton (NJ), pp. 94-119, 1963.

[13] Wöhe, G. and Döring, U., Einführung in die Allgemeine Betriebswirtschaftslehre, Vahlen-Verlag: München, pp. 386-387, 2005.

[14] Geiger, C. and Kanzow, C., Theorie und Numerik restringierter Optimierungsaufgaben, Springer-Verlag: Berlin, Heidelberg and New York, pp. 77-120, 2002.

[15] Albrecht, S., Beck, T., Barthel, L., Fischer, M. The Sustainability of Packaging Systems for Fruit and Vegetable Transport in Europe based on Life-Cycle-Analysis - Update 2009. On behalf of Stiftung Initiative Mehrweg SIM (Foundation for Reusable Systems under German Civil Law)). Stuttgart/Michendorf, pp. 17-98, 2009. 